\title{
Common polymorphisms in nitric oxide synthase (NOS) genes influence quality of aging and longevity in humans
}

\author{
Alberto Montesanto $\cdot$ Paolina Crocco $\cdot$ Federica Tallaro $\cdot$ Francesca Pisani $\cdot$ \\ Bruno Mazzei - Vincenzo Mari - Andrea Corsonello • Fabrizia Lattanzio • \\ Giuseppe Passarino • Giuseppina Rose
}

Received: 29 January 2013/ Accepted: 3 April 2013

(C) Springer Science+Business Media Dordrecht 2013

\begin{abstract}
Nitric oxide (NO) triggers multiple signal transduction pathways and contributes to the control of numerous cellular functions. Previous studies have shown in model organisms that the alteration of NO production has important effects on aging and lifespan. We studied in a large sample (763 subjects, age range 19-107 years) the variability of the three human genes (NOS1, -2, -3) coding for the three isoforms of the NADPH-dependent enzymes named NO synthases (NOS) which are responsible of NO synthesis. We have then verified if the variability of these genes is associated with longevity, and with a number of geriatric parameters. We found that gene variation of
\end{abstract}

Alberto Montesanto and Paolina Crocco contributed equally to this study.

Electronic supplementary material The online version of this article (doi:10.1007/s10522-013-9421-z) contains supplementary material, which is available to authorized users.

A. Montesanto · P. Crocco - F. Tallaro .

F. Pisani - G. Passarino - G. Rose ( $\square)$

Department of Biology, Ecology and Earth Science,

University of Calabria, 87036 Rende, Italy

e-mail:pinarose@unical.it

B. Mazzei · V. Mari · A. Corsonello

Italian National Research Center on Aging (INRCA), 87100 Cosenza, Italy

F. Lattanzio

Scientific Direction of Italian National Research Center on Aging (INRCA), 60124 Ancona, Italy
NOS1 and NOS2 was associated with longevity. In addition NOS1 rs1879417 was also found to be associated with a lower cognitive performance, while NOS2 rs2297518 polymorphism showed to be associated with physical performance. Moreover, SNPs in the NOS1 and NOS3 genes were respectively associated with the presence of depression symptoms and disability, two of the main factors affecting quality of life in older individuals. On the whole, our study shows that genetic variability of NOS genes has an effect on common age related phenotypes and longevity in humans as well as previously reported for model organisms.

Keywords NOS $\cdot$ Longevity $\cdot$ Aging $\cdot$ Nitric oxide · Polymorphisms

\section{Introduction}

Nitric oxide (NO) is one of the most widespread signaling molecules in nature. By interacting with different intracellular targets, NO triggers multiple signal transduction pathways thus contributing to the control of almost every cellular function (Liaudet et al. 2000). NO is produced during the oxidation of L-arginine to L-citrulline by a family of NADPHdependent enzymes named NO synthases (NOS), with three isoforms in mammals encoded by three distinct NOS genes, named neuronal ( $n N O S$ or NOS1), inducible ( $i N O S$ or NOS2), and endothelial (eNOS or NOS3). Although all isoforms share a similar 
structure, the mechanisms that control their activity are quite different. NOS1 and NOS3 are constitutively expressed and $\mathrm{Ca}^{2+} /$ calmodulin-dependent, while the inducible form (NOS2) is induced by inflammatory stimuli and is $\mathrm{Ca}^{2+} /$ calmodulin-independent (Förstermann and Sessa 2012). The activity of each of these isoforms is fine-tuned by a variety of transcriptional and post-translational modifications, which may also influence the specific targeting of NOS to subcellular compartments (Oess et al. 2006). Although all three isoforms can be found in numerous tissues, the specific cell type where NOS enzymes are located is of critical importance in determining the specific outcomes of the NO signalling pathways (Villanueva and Giulivi 2010). In neuronal cells NO, which is produced principally by $N O S 1$, functions as regulator of neuronal transmission, cerebral blood flow and synaptic plasticity thus acting as a neuromodulator and neuroprotective agent (Calabrese et al. 2007; Feil and Kleppisch 2008; Garthwaite 2008). In endothelial cells NO, mainly produced by NOS3, acts as a regulator of vascular homeostasis being involved in the regulation of smooth muscle relaxation, and in the inhibition of platelet aggregation (Kader et al. 2000; Moncada and Higgs 2006). NO produced by NOS2 particularly in macrophages, is mainly involved in the maintenance of the immune-inflammatory response (Moilanen et al. 1997; Wink et al. 2011). The biological effects of NO, however, largely depend on the amount of NO produced. High amounts of NO or its derivative reactive nitrogen species (RNS), such as peroxynitrite (ONOO-), a highly reactive radical produced by the reaction between $\mathrm{NO}$ and superoxide anion $\left(\mathrm{O}_{2}{ }^{-}\right)$, can trigger nitrosative modifications of proteins, lipids and nucleic acids, which in turn may impinge on cellular signaling pathways leading to cytotoxicity, neurodegeneration, and apoptotic cell death (Beckman and Koppenol 1996; Pacher et al. 2007; Calcerrada et al. 2011).

Oxidative stress is a well established hallmark of the aging process and there is strong evidence for a causal role of NO and RNS therein (McCann et al. 1998; Drew and Leeuwenburgh 2002; Torregrossa et al. 2011). Markers of nitrosative stress injury, such as nitrosylation and nitration of proteins, have been shown to increase as a function of age (Toprakci et al. 2000; Kanski et al. 2005; Kim et al. 2006). Moreover, a growing number of studies indicate that the availability and biological activity of $\mathrm{NO}$ is impaired during aging, and that this is a key contributing factor to the onset of age related phenotypes such as vascular and brain aging (van der Loo et al. 2000; Taddei et al. 2001; Napoli and Ignarro 2009; Brown 2010; Kawamoto et al. 2012). Although the enhanced production of $\mathrm{O}_{2}{ }^{-}$ that accompanies the aging process, as well as the agerelated depletion of some essential NOS substrates and cofactors, may affect the amount of bioavailable NO, an impaired activity and expression of NOSs has been reported to occur with age which contributes to alterations in NO signaling, and to the subsequent failure of many of the body's physiological processes (Yang et al. 2004; Strosznajder et al. 2004; Yoon et al. 2010; Cau et al. 2012; Jung et al. 2012).

Supportive evidence for a role of NOSs in healthy aging and lifespan extension has come from studies with knockout models. It has been shown, for instance, that in mice lacking all three NOS isoforms the survival rate is reduced by $80 \%$ (Tsutsui et al. 2009). Moreover, a reduction in survival rate of about $50 \%$, and an attenuation of caloric restriction-induced life extension has been observed in nos 3 knockout mice (Dere et al. 2002; Nisoli et al. 2005).

Given this background, the present paper addresses the hypothesis that NOS genetic variants affect human aging and longevity. We analyzed common and potentially functional NOS SNPs in a sample group of 763 individuals from the south of Italy ranging from 19 to 107 years of age. Moreover, since the increase with age in ROS/RNS-mediated stress is accompanied by the deterioration of cognitive and physical abilities, which is one of the most important components of the quality of life in the elderly that adversely affects successful aging and longevity, we also explored the impact of NOSs variability on cognitive and physical performances. In this case, subjects aged 65-91 years, that is the age range where a significant increase of overall impairments occur, were analyzed.

\section{Materials and methods}

Sample

The sample analyzed in the present study included 763 (417 females and 346 males) 19-107 years old subjects (median age 81 years). All subjects were born in Calabria (southern Italy) and their parents and grandparents were native of the same area. 
The sample was collected during several campaigns of recruitment (De Rango et al. 2011). Subjects older than 65 years went through a multidimensional geriatric assessment carried out by a geriatrician. In addition, each of these subjects was submitted to a home based interview by a trained operator, with the administration of a structured questionnaire for the collection of socio-demographic information, evaluation of physical, cognitive, depressive status, sensory deficits, medications, and self-reported health status. Subjects with dementia and/or neurologic disorders were not included. White blood cells (WBC) from blood buffy coats were used as source of DNA.

The analyses were carried out by dividing the sample into two sex- and age-specific classes obtained according to the survival functions of the Italian population from 1890 onward (Passarino et al. 2006). In particular, the graphs of the second derivative of these survival functions indicated that at 88 years for males and 91 for females a significant change in the slope of these functions occurs. We used these two age and sex-specific cut-offs to categorize the sample into rationally defined "thresholds of longevity". For this reason in the present study men younger than 88 and women younger than 91 years will be defined as controls $(N=442)$, while men older than 88 and women older than 91 years will be defined as cases $(N=321)$.

\section{Ethics statement}

All the subjects gave their written informed consent to use their anonymous genetic and phenotypic data for genetic studies on aging and longevity. The recruitment campaigns received the approval of the Ethical committee of the University of Calabria.

\section{SNPs selection}

Polymorphisms within the NOS genes were selected from literature data, and using information from public databases (http://www.ncbi.nih.gov/, http://www.hap map.org/). The a priori selection was based on the following criteria: minor allele frequency (MAF) $>10 \%$ in Caucasians, putative functional significance (non-synonymous SNPs, SNPs located in the 5'- and 3'-UTR regions), SNPs previously investigated in association studies. For each gene the selected SNPs are reported in Table 1.
Table 1 Polymorphisms within the NOS genes analysed in the present study

\begin{tabular}{|c|c|c|c|c|}
\hline $\begin{array}{l}\text { Gene } \\
\text { symbol }\end{array}$ & dbSNP ID & $\begin{array}{l}\text { Allele } \\
\text { (major/ } \\
\text { minor) }\end{array}$ & $\begin{array}{l}\text { Physical } \\
\text { location }\end{array}$ & $\begin{array}{l}\text { Function } \\
\text { annotation }\end{array}$ \\
\hline \multirow[t]{2}{*}{ NOS1 } & rs1879417 & $\mathrm{T} / \mathrm{C}$ & Promoter & \\
\hline & rs2682826 & $\mathrm{C} / \mathrm{T}$ & $3^{\prime}$ UTR & \\
\hline \multirow[t]{2}{*}{ NOS2 } & rs 10459953 & $\mathrm{G} / \mathrm{C}$ & $5^{\prime} \mathrm{UTR}$ & \\
\hline & rs2297518 & G/A & Exon 16 & Ser608Leu \\
\hline \multirow[t]{2}{*}{ NOS3 } & rs 10277237 & $\mathrm{G} / \mathrm{A}$ & Promoter & \\
\hline & rs1799983 & $\mathrm{G} / \mathrm{T}$ & Exon 7 & Asp298Glu \\
\hline
\end{tabular}

Geriatric assessment

The variability of genes that we tested for association with longevity was also investigated in relation to accepted biomarkers of the aging process that evaluate physical, cognitive, and psychological status in the elderly population. To this purpose a subgroup of the control sample whose subjects underwent a geriatric assessment (subjects 65-91 years of age) was further analyzed $(N=317)$.

Functional activity

The management of activities of daily living (bathing, dressing, toileting, transfer from bed to chair and feeding) was assessed using a modification of the Katz' Index of ADL (Katz et al. 1970). The assessment was based on what the subject was able to do at the time of the visit. The score is given counting the number of activities in which the participant is dependent or independent at the time of the visit. In our analyses ADL scores were dichotomized as one if the subject was not independent in all five items and zero otherwise.

\section{Physical performance}

Hand grip (HG) strength was measured by using a handheld dynamometer (SMEDLEY's dynamometer TTM) while the subject was sitting with the arm close to his/her body. The test was repeated three times with the stronger hand. The maximum of these values was used in the analyses. Since HG strength is affected by age, sex and height, the scores were corrected for these factors. When a test was not carried out, it was specified if it was due to physical disabilities or because the subject refused to participate. 
Depression

The Geriatric Depression Scale (GDS) is an instrument designed to measure depression in the elderly consisting of a series of yes/no questions in reference to how they felt on the day of administration (Sheikh and Yesavage 1986). A score above five is suggestive of moderate depression, while a score above ten is suggestive of severe depression. In our analyses GDS scores were dichotomized as one if the subject showed depression symptoms (GDS > 5) and zero otherwise.

\section{Cognitive performance}

Mini mental state examination (MMSE) test was used to evaluate the cognitive performance in the analysed sample. It is a 30 -item questionnaire that assesses orientation, episodic memory, attention, language, and construction functions (Folstein et al. 1975). Since the test is affected by age and educational status, the MMSE scores were normalized for these variables according to a standardized procedure (Grigoletto et al. 1999). In our analyses MMSE scores were dichotomized as 1 if the subject showed a normal cognitive function (MMSE $\geq 23$ ) and zero otherwise.

\section{Statistical analyses}

For each polymorphism of the NOS genes, allele frequencies were estimated by counting genes from the observed genotypes. The Hardy-Weinberg equilibrium (HWE) was tested using the exact test proposed by Wigginton et al. (2005). Standard errors for alleles were computed according to the hypothesis of the multinomial distribution. Pairwise measures of linkage disequilibrium (LD) between the analyzed loci were calculated with the Haploview 4.2 (Barrett et al. 2005). The amount of LD was quantified by Lewontin's coefficient $\left(\mathrm{D}^{\prime}\right)$.

\section{Single-locus analysis}

In order to test the association between the analysed phenotypes and the variability of the NOS genes the RobustSNP algorithm (a robust association test suitable for both quantitative and binary traits which also takes into account covariates) recently proposed by So and Sham (2011) was adopted. This test was based on the score test and has been implemented in the $\mathrm{R}$ package RobustSNP.

In the present study the RobustSNP algorithm will be applied to estimate how the variability of genes analyzed in the present study influences (i) the predisposition to human longevity (ii) the variability of functional parameters including cognitive function, functional performance and depression status. In particular, in the regression models used to test the association between the variability of analyzed genes and the human longevity, the variable sex was used as covariate In the association analyses involving the functional parameters, covariate adjustment included sex, age and height when HG scores were analyzed, only age and sex when disability and depression status were investigated. As mentioned before MMSE scores were normalized for age and educational status according to a standardized procedure reported in Grigoletto et al. (1999).

Interaction analysis

In order to explore the interaction effects between the analyzed polymorphisms on the analyzed phenotypes (longevity and functional parameters), the recently developed Model-based multifactor dimensionality reduction (MB-MDR) algorithm will be applied (Calle et al. 2010).

\section{Results}

Genetic analyses

Table 2 summarizes the main characteristics of the analyzed sample stratified by age-group as previously defined. The age distributions in males and females are reported in supplementary Fig. 1.

Supplementary Table 1 shows the genotype frequencies in cases and controls. All SNPs followed the HWE in the control group $(p>0.05)$. No linkage disequilibrium was detected at any of the loci.

NOS gene polymorphisms and longevity

Different genetic models (dominant, additive and recessive) were used to test association, using for each SNP the minor allele as reference. Table 3 shows 
Table 2 Socio-demographic characteristics and functional parameters (ADL, HG, GDS and MMSE) in the total sample and stratified for group membership

\begin{tabular}{|c|c|c|c|}
\hline & $\begin{array}{l}\text { Controls } \\
(N=442)^{\mathrm{a}}\end{array}$ & $\begin{array}{l}\text { Cases } \\
(N=321)^{\mathrm{a}}\end{array}$ & $\begin{array}{l}\text { Total } \\
(N=763)\end{array}$ \\
\hline \multicolumn{4}{|l|}{ Age } \\
\hline Mean (SD) & $64.9(18.1)$ & $96.2(3.3)$ & $78.2(20.8)$ \\
\hline Range & $19-91$ & 89-107 & 19-107 \\
\hline \multicolumn{4}{|c|}{ Body mass index (BMI) } \\
\hline Mean (SD) & $27.1(4.3)$ & $23.3(4.1)$ & $25.1(4.6)$ \\
\hline Range & $15.01-45.35$ & $12.98-40.55$ & $12.98-45.35$ \\
\hline \multicolumn{4}{|l|}{ Hand grip strength ${ }^{\mathrm{b}}$} \\
\hline Mean (SD) & $22.24(9.40)$ & $12.67(6.47)$ & $16.99(9.24)$ \\
\hline Range & $4.00-55.00$ & $0.00-42.0$ & $0.00-55.00$ \\
\hline \multicolumn{4}{|c|}{ Activities of daily living $(\mathrm{ADL})^{\mathrm{b}}[n(\%)]$} \\
\hline Disable $(<5)$ & $55(17.4)$ & $220(68.5)$ & $275(43.1)$ \\
\hline Non disable $(=5)$ & $262(82.6)$ & $101(31.5)$ & $363(56.9)$ \\
\hline \multicolumn{4}{|c|}{ Geriatric Depression Scale (GDS) $^{\mathrm{b}}[n(\%)]$} \\
\hline Depressed $(\geq 5)$ & $107(33.8)$ & $74(23.1)$ & $181(28.4)$ \\
\hline Non depressed $(<5)$ & $210(66.2)$ & $247(76.9)$ & 457 (71.6) \\
\hline \multicolumn{4}{|c|}{ Mini mental state examination $(\mathrm{MMSE})^{\mathrm{c}}[n(\%)]$} \\
\hline Normal $(\geq 23)$ & $202(66.66)$ & - & \\
\hline Impaired $(<23)$ & $101(33.33)$ & & \\
\hline
\end{tabular}

ADL scores were dichotomized as one if the subject was not independent in all 5 items and 0 otherwise. GDS scores were dichotomized as 1 if the subject showed depression symptoms (GDS > 5) and 0 otherwise (see "Materials and Methods")

${ }^{a}$ Men younger than 88 and women younger than 91 years will be defined as controls. Men older than 88 and women older than 91 years will be defined as cases

b Data available only for subjects older than 65 years

${ }^{c}$ Data available only for subjects belonging to the control group older than 65 years

results obtained using the RobustSNP algorithm. After adjusting for sex, we found that NOS1 rs1879417 and NOS2 rs2297518 were significantly associated with the longevity phenotype. The additive model for rs1879417 and the recessive one for rs2297518 resulted to be the most likely genetic models, in which the presence of the relevant alleles (allele $\mathrm{C}$ for rs1879417 and allele A for rs2297518 variation) decreases the probability to attain longevity ( $\mathrm{p}_{\text {Model }}=0.008$ and $\mathrm{p}_{\text {Model }}=0.031$, respectively). After adjusting for multiple testing (due to the three different tested genetic models), the NOS1 rs1879417 remained statistically significant $\left(\mathrm{p}_{\text {Adj }}=0.018\right)$, while NOS2 rs2297518 remained only marginally associated with longevity $\left(\mathrm{p}_{\text {Adj }}=0.066\right)$.

NOS gene polymorphisms and functional parameters

Subjects 65-91 years of age $(N=317)$ were further analyzed for examining the association between the variability of NOS genes and physical (HG and ADL) and cognitive (MMSE and GDS) abilities. Table 4 reports the results of the association tests for the three genetic models using the minor allele for each SNP as reference, and after adjusting for the appropriate parameters (see "Materials and Methods").

The NOS1 rs1879417 was found significantly associated with cognitive performance in an additive manner $\left(\mathrm{p}_{\text {Model }}=0.045\right.$ ) with subjects carrying the less frequent $\mathrm{C}$ allele showing lowest MMSE scores. However, after adjustment for multiple comparisons this association failed to reach statistical significance $\left(\mathrm{p}_{\text {Adj }}=0.093\right.$ ). In addition, we found that NOSI rs2682826 variation significantly influenced the GDS performance $\left(\mathrm{p}_{\text {Model }}=0.015\right)$. Subjects with at least one $\mathrm{T}$ allele (less frequent allele) showed a significant higher probability to have depression symptoms than subjects homozygous for the allele $G$ (dominant model). After adjustment for multiple comparisons this association remained statistically significant $\left(\mathrm{p}_{\text {Adj }}=0.033\right)$.

A borderline association was observed between NOS2 rs2297518 and HG scores ( $\mathrm{p}_{\text {Model }}=0.049$ ), with subjects homozygous for the less frequent allele A showing higher HG scores than those carrying at least one copy of the wild type $\mathrm{G}$ allele.

Finally, a significant association was found between NOS3 rs10277237 and ADL performance $\left(\mathrm{p}_{\text {Model }}=0.002\right)$ with subjects homozygous for the minor allele $\mathrm{A}$ (recessive model) showing significantly lower probability to be disable than those carrying at least one $G$ allele. After adjustment for multiple comparisons this association remained statistically significant $\left(\mathrm{p}_{\text {Adj }}=0.004\right)$.

Interaction analysis

By using the MB-MDR approach, we did not find any significant interaction effect among the NOS gene polymorphisms and the analysed phenotypes. 
Table 3 Results of the RobustSNP association test with the longevity phenotype in the analyzed sample

\begin{tabular}{|c|c|c|c|c|c|c|}
\hline SNP & Gene & MAF & $z$-score & $\mathrm{p}_{\text {Model }}$ & Model & $\mathrm{p}_{\mathrm{Adj}}$ \\
\hline rs1879417 & NOS1 & 49.0 & -2.659 & 0.008 & Additive & 0.018 \\
\hline rs2682826 & & 37.0 & 0.919 & 0.358 & Recessive & 0.589 \\
\hline rs10459953 & NOS2 & 29.5 & -1.022 & 0.307 & Additive & 0.522 \\
\hline rs2297518 & & 25.3 & -2.163 & 0.031 & Recessive & 0.066 \\
\hline rs10277237 & NOS3 & 29.0 & -0.574 & 0.566 & Dominant & 0.805 \\
\hline rs1799983 & & 32.5 & 0.743 & 0.457 & Dominant & 0.703 \\
\hline
\end{tabular}

Model refers to the most likely genetic model among the dominant (DOM), recessive (REC) and additive (ADD) ones. pmodel refers to the $p$ value for the most likely genetic model. $\mathrm{p}_{\text {Adj }}$ refers to the $p$ value adjusted for multiple comparisons (due to the three different tested genetic models). $z$-score represents the $z$-statistics for the regression analyses

$M A F$ minor allele frequency

\section{Discussion}

Nitrosative stress is now widely recognized as a significant causal factor in the physiological decline that characterizes the aging process in many tissues. Age-related alterations in nitric oxide synthase activity and/or expression and the consequent alterations in NO production and bioactivity are likely to contribute to this decline.

In the present study, we provide evidence that the variability of NOS genes affects common age related phenotypes and longevity. We found an association between NOS1-rs1879417 $\left(\mathrm{p}_{\text {Model }}=0.008 ; \mathrm{p}_{\text {Adj }}=\right.$ 0.018 ) and NOS2-rs2297518 ( $\mathrm{p}_{\text {Model }}=0.031 ; \mathrm{p}_{\text {Adj }}=$ 0.066 ) and longevity, indicating that variation in these genes may influence human aging and lifespan.

The analysis of a subgroup of subjects in the age range 65-91 years showed that the same variants were also weakly associated with geriatric parameters that are predictors of the age related physiological decline. In particular, the NOS1 rs1879417-C allele, that we found associated with a lower probability of survival to very old age, was also associated with lower cognitive performance (MMSE score $<23$ ). This association is in line with several evidences. First, it is well established that the glutamate-NO-cGMP pathway plays a role in learning and memory processes and cognitive performance during aging (DomekŁopacińska and Strosznajder 2010; Paul and Ekambaram 2011). Second, recent studies indicate that nos 1 knockout mice have impaired cognitive functions (Kirchner et al. 2004; Weitzdoerfer et al. 2004; Zoubovsky et al. 2011). Third, changes in the expression and/or activity of NOS1 have been observed in different cognitive brain areas of aged rats and senescence accelerated mice (SAM), a murine model of age-related cognitive impairment and deterioration of learning and memory (Law et al. 2002; Colas et al. 2006; Han et al. 2010). It is also of interest that the rs1879417 is located in the promoter region of NOS1, upstream of a fairly complex transcriptional regulatory region (Bros et al. 2006). Polymorphisms in this region, which affect gene expression and neuronal transcriptome, have been associated with neurological disorders such as schizophrenia and Alzheimer's disease (Reif et al. 2011a, b). Based on this, it is conceivable that the association observed might reflect the linkage disequilibrium between the rs1879417 and these functional variants.

As for NOS2 gene, we also found that the rs2297518 has a modest impact on HG strength, one of the most effective death predictor in the elderly.

This finding is consistent with researches reporting that the NOS2/NO/ONOO- overproduction induced by $\mathrm{TNF} \alpha$ via $\mathrm{NF}-\kappa \mathrm{B}$ may be one of the underlying causes of sarcopenia (Hall et al. 2011). Our finding that the rs2297518-A allele, which reduces the chance of survival to very old age, is associated with higher HG scores seems somehow in contrast with the idea that higher $\mathrm{HG}$ strength is predictive of increased survival in the elderly population. This result is just weakly significant, and certainly needs to be verified. On the other hand it may reflect pleiotropic contrasting effects and functions of the iNOS NO in different cell types In this view, it can be hypothesized that the possible harmful effect exerted by the rs2297518-A allele in some cell-types (for instance a low NO production in macrophages) is more relevant for 
survival than its beneficial effect in other cell-types (i.e. low production of RNS in muscle cells).

For two of the six variants analyzed we found association with geriatric conditions but not with longevity. Specifically the SNP rs2682826 in the NOS1 gene and the SNP rs10277237 in the NOS3 gene were respectively associated with GDS $\left(\mathrm{p}_{\text {Model }}=0.015 ; \mathrm{p}_{\text {Adj }}=0.033\right)$ and Activity of Daily Living ( $\left.\mathrm{p}_{\text {Model }}=0.002 ; \mathrm{p}_{\text {Adj }}=0.004\right)$, two of the main factors affecting quality of life in older individuals. Depression is a complex disorder where, inflammation, oxidative/nitrosative stress, and reduced hippocampal neurogenesis make a substantial contribution (Maes et al. 2009). It has been found that NOS1-derived NO negatively affects neurogenesis and that the overexpression of NOS1 in the hippocampus following chronic mild stress exposure suppresses hippocampal neurogenesis and induces depression (Zhou et al. 2007). We found that carriers of the minor rs2682826-T allele have a higher probability to be depressed. In line with our observation, the rs2682826-T allele has been found to be a susceptibility factor for recurrent depressive disorder, and for traits where depression is a comorbidity factor such as Parkinson disease (Gałecki et al. 2011; Hancock et al. 2008). The rs2682826 is located in the $3^{\prime} \mathrm{UTR}$ of exon 29 , downstream from the translation termination site of the NOS1 (C276T). Differences in protein production elicited by this variation, that lies close to several miRNAs binding sites (Ibarrola-Villava et al. 2011) could be at the basis of the observed association.

Another interesting finding of our study was the association between the NOS3 rs10277237 and ADL scores. Subjects homozygous for the rs10277237-A allele had significantly better ADL performance compared with subjects with the other two genotypes. The inability of older adults to perform basic self care independently is a consequence of a decline in physiological functions of multiple tissues. A contributor to this general decay is likely to be the reduction in endothelial cell function caused by the age-related impairment in the release of NO by NOS3. Indeed, this has the effect of reducing blood flow to all tissues in the body and thus the availability of nutrients for energy needs. Age-related changes in energy production and fuel utilization via mitochondrial dysfunction may also contribute to the decline in physical performance and disability among older adults. To this regard, evidence in literature indicate that NO 
generation by NOS3 is required for mitochondrial biogenesis and function. In fact, $\operatorname{nos} 3^{-1-}$ mice have fewer mitochondria, and lower $\beta$-oxidative activity and energy expenditure than wild-type controls (Nisoli et al. 2003; Le Gouill et al. 2007). In this context, it is also worth noting that recent studies have reported the existence of a mitochondrial NOS (mtNOS) isoform that seems to be both constitutive, mainly a posttranslational isoform of NOS1, and inducible (Elfering et al. 2000; Lòpez et al. 2006; Finocchietto et al. 2009). Because of its action on complex I and IV, NO in mitochondria may have important effects on oxidative phosphorylation and ROS/RNS production (Finocchietto et al. 2009). These effects may be amplified in a pro-oxidant environment like in the case of aged individuals, with consequences particularly in tissues such as brain and skeletal muscle which are highly dependent on mitochondrial function.

In conclusion, it is worth mentioning that the causative genetic variations in LD with the studied SNPs remain to be identified and that the associations between NOS alleles and aging phenotypes we observed, in most cases would not hold after Bonferroni correction for multiple comparisons, indicating that it will be useful to replicate this study. On the other hand, this study availed of a population (Calabria, Southern Italy) which is characterized by high genetic homogeneity and a scarce level of immigration due to geographical, historical and social reasons. Consequently it is likely we avoided false positive results due to population stratification. On the other hand, it is also important to underline that all the results were in line with previous data and in particular with data from model organisms. This allows us to consider NOS genes to have an important role on the age related homeostatic and physiological decline which is at the basis of most of the age related phenotypes and longevity (Fried et al. 2001; Montesanto et al. 2010).

Acknowledgments The research leading to these results has received funding from the European Union's Seventh Framework Programme (FP7/2007-2011) under Grant agreement No. 259679 and from "Fondi di Ateneo" of the University of Calabria.

\section{References}

Barrett JC, Fry B, Maller J, Daly MJ (2005) Haploview: analysis and visualization of $\mathrm{LD}$ and haplotype maps. Bioinformatics 21:263-265
Beckman JS, Koppenol WH (1996) Nitric oxide, superoxide, and peroxynitrite: the good, the bad, and ugly. Am J Physiol 271:C1424-C1437

Bros M, Boissel JP, Gödtel-Armbrust U, Förstermann U (2006) Transcription of human neuronal nitric oxide synthase mRNAs derived from different first exons is partly controlled by exon 1-specific promoter sequences. Genomics 87:463-473

Brown GC (2010) Nitric oxide and neuronal death. Nitric Oxide 23:153-165

Calabrese V, Mancuso C, Calvani M, Rizzarelli E, Butterfield DA, Stella AM (2007) Nitric oxide in the central nervous system: neuroprotection versus neurotoxicity. Nat Rev Neurosci 8:766-775

Calcerrada P, Peluffo G, Radi R (2011) Nitric oxide-derived oxidants with a focus on peroxynitrite: molecular targets, cellular responses and therapeutic implications. Curr Pharm Des 17:3905-3932

Calle ML, Urrea V, Malats N, Van Steen K (2010) mbmdr: an R package for exploring gene-gene interactions associated with binary or quantitative traits. Bioinformatics 26:2198-2199

Cau SB, Carneiro FS, Tostes RC (2012) Differential modulation of nitric oxide synthases in aging: therapeutic opportunities. Front Physiol 3:218

Colas D, Gharib A, Bezin L, Morales A, Guidon G, Cespuglio R, Sarda N (2006) Regional age-related changes in neuronal nitric oxide synthase (nNOS), messenger RNA levels and activity in SAMP8 brain. BMC Neurosci 7:81

De Rango F, Montesanto A, Berardelli M, Mazzei B, Mari V, Lattanzio F, Corsonello A, Passarino G (2011) To grow old in southern Italy: a comprehensive description of the old and oldest old in Calabria. Gerontology 57:327-334

Dere E, De Souza Silva MA, Topic B, Fiorillo C, Li JS, Sadile AG, Frisch C, Huston JP (2002) Aged endothelial nitric oxide synthase knockout mice exhibit higher mortality concomitant with impaired open-field habituation and alterations in forebrain neurotransmitter levels. Genes Brain Behav 1:204-213

Domek-Łopacińska KU, Strosznajder JB (2010) Cyclic GMP and nitric oxide synthase in aging and Alzheimer's disease. Mol Neurobiol 41:129-137

Drew B, Leeuwenburgh C (2002) Aging and the role of reactive nitrogen species. Ann NY Acad Sci 959:66-81

Elfering SL, Sarkela TM, Giulivi C (2000) Biochemistry of mitochondrial nitric-oxide synthase. J Biol Chem 277:38079-38086

Feil R, Kleppisch T (2008) NO/cGMP-dependent modulation of synaptic transmission. Handb Exp Pharmacol 184:529-560

Finocchietto PV, Franco MC, Holod S, Gonzalez AS, Converso DP, Arciuch VG, Serra MP, Poderoso JJ, Carreras MC (2009) Mitochondrial nitric oxide synthase: a masterpiece of metabolic adaptation, cell growth, transformation, and death. Exp Biol Med (Maywood) 234:1020-1028

Folstein MF, Folstein SE, McHugh PR (1975) "Mini-mental state". A practical method for grading the cognitive state of patients for the clinician. J Psychiatr Res 12:189-198

Förstermann U, Sessa WC (2012) Nitric oxide synthases: regulation and function. Eur Heart J 33:829-837

Fried LP, Tangen CM, Walston J, Newman AB, Hirsch C, Gottdiener J, Seeman T, Tracy R, Kop WJ, Burke G, 
McBurnie MA (2001) Cardiovascular health study collaborative research group. Frailty in older adults: evidence for a phenotype. J Gerontol A 56:M146-M156

Gałecki P, Maes M, Florkowski A, Lewiński A, Gałecka E, Bienkiewicz M, Szemraj J (2011) Association between inducible and neuronal nitric oxide synthase polymorphisms and recurrent depressive disorder. J Affect Disord 129:175-182

Garthwaite J (2008) Concepts of neural nitric oxide-mediated transmission. Eur J Neurosci 27:2783-2802

Grigoletto F, Zappalà G, Anderson DW, Lebowitz BD (1999) Norms for the mini-mental state examination in a healthy population. Neurology 53:315-320

Hall DT, Ma JF, Marco SD, Gallouzi IE (2011) Inducible nitric oxide synthase (iNOS) in muscle wasting syndrome, sarcopenia, and cachexia. Aging (Albany NY) 3:702-715

Han S, Rudd JA, Hu ZY, Zhang L, Yew DT, Fang M (2010) Analysis of neuronal nitric oxide synthase expression and increasing astrogliosis in the brain of senescence-accelerated-prone 8 mice. Int J Neurosci 120:602-608

Hancock DB, Martin ER, Vance JM, Scott WK (2008) Nitric oxide synthase genes and their interactions with environmental factors in Parkinson's disease. Neurogenetics 9:249-262

Ibarrola-Villava M, Peña-Chilet M, Fernandez LP, Aviles JA, Mayor M, Martin-Gonzalez M, Gomez-Fernandez C, Casado B, Lazaro P, Lluch A, Benitez J, Lozoya R, Boldo E, Pizarro A, Martinez-Cadenas C, Ribas G (2011) Genetic polymorphisms in DNA repair and oxidative stress pathways associated with malignant melanoma susceptibility. Eur J Cancer 47:2618-2625

Jung J, Na C, Huh Y (2012) Alterations in nitric oxide synthase in the aged CNS. Oxid Med Cell Longev 2012:718976

Kader KN, Akella R, Ziats NP, Lakey LA, Harasaki H, Ranieri JP, Bellamkonda RV (2000) eNOS-overexpressing endothelial cells inhibit platelet aggregation and smooth muscle cell proliferation in vitro. Tissue Eng 6:241-251

Kanski J, Hong SJ, Schöneich C (2005) Proteomic analysis of protein nitration in aging skeletal muscle and identification of nitrotyrosine-containing sequences in vivo by nanoelectrospray ionization tandem mass spectrometry. J Biol Chem 280:24261-24266

Katz S, Downs TD, Cash HR, Grotz RC (1970) Progress in development of the index of ADL. Gerontologist 10:20-30

Kawamoto EM, Vasconcelos AR, Degaspari S, Böhmer AE, Scavone $\mathrm{C}$ et al (2012) Age-related changes in nitric oxide activity, cyclic GMP, and TBARS levels in platelets and erythrocytes reflect the oxidative status in central nervous system. Age (Dordr) 35(2):331-342

Kim CH, Zou Y, Kim DH, Kim ND, Yu BP, Chung HY (2006) Proteomic analysis of nitrated and 4-hydroxy-2- nonenalmodified serum proteins during aging. J Gerontol A 61:332-338

Kirchner L, Weitzdoerfer R, Hoeger H, Url A, Schmidt P, Engelmann M, Villar SR, Fountoulakis M, Lubec G, Lubec B (2004) Impaired cognitive performance in neuronal nitric oxide synthase knockout mice is associated with hippocampal protein derangements. Nitric Oxide 11:316-330

Law A, O’Donnell J, Gauthier S, Quirion R (2002) Neuronal and inducible nitric oxide synthase expressions and activities in the hippocampi and cortices of young adult, aged cognitively unimpaired, and impaired Long-Evans rats. Neuroscience 112:267-275

Le Gouill E, Jimenez M, Binnert C, Pierre-Yves J, Thalmann S, Nicod P, Scherrer U, Vollenweider P (2007) eNOS knockout mice have defective mitochondrial beta-oxidation. Diabetes 56:2690-2696

Liaudet L, Soriano FG, Szabó C (2000) Biology of nitric oxide signaling. Crit Care Med 28:N37-N52

Lòpez LC, Escames G, Tapias V, Utrilla P, Leo'n J, AcunaCastroviejo D (2006) Identification of an inducible nitric oxide synthase in diaphragm mitochondria from septic mice: its relation with mitochondrial dysfunction and prevention by melatonin. Int $\mathrm{J}$ Biochem Cell Biol 38:267-278

Maes M, Yirmyia R, Noraberg J, Brene S, Hibbeln J, Perini G, Kubera M, Bob P, Lerer B, Maj M (2009) The inflammatory \& neurodegenerative (I\&ND) hypothesis of depression: leads for future research and new drug developments in depression. Metab Brain Dis 24:27-53

McCann SM, Licinio J, Wong ML, Yu WH, Karanth S, Rettori V (1998) The nitric oxide hypothesis of aging. Exp Gerontol 33:813-826

Moilanen E, Moilanen T, Knowles R, Charles I, Kadoya Y, AlSaffar N, Revell PA, Moncada S (1997) Nitric oxide synthase is expressed in human macrophages during foreign body inflammation. Am J Pathol 150:881-887

Moncada S, Higgs EA (2006) The discovery of nitric oxide and its role in vascular biology. Br J Pharmacol 147:S193S201

Montesanto A, Lagani V, Martino C, Dato S, De Rango F, Berardelli M, Corsonello A, Mazzei B, Mari V, Lattanzio F, Conforti D, Passarino G (2010) A novel populationspecific approach to define frailty. Age (Dordr) 32(3):385-395

Napoli C, Ignarro LJ (2009) Nitric oxide and pathogenic mechanisms involved in the development of vascular diseases. Arch Pharm Res 32:1103-1108

Nisoli E, Clementi E, Paolucci C, Cozzi V, Tonello C, Sciorati C, Bracale R, Valerio A, Francolini M, Moncada S, Carruba MO (2003) Mitochondrial biogenesis in mammals: the role of endogenous nitric oxide. Science 299:896-899

Nisoli E, Tonello C, Cardile A, Cozzi V, Bracale R, Tedesco L, Falcone S, Valerio A, Cantoni O, Clementi E, Moncada S, Carruba MO (2005) Calorie restriction promotes mitochondrial biogenesis by inducing the expression of eNOS. Science 310:314-317

Oess S, Icking A, Fulton D, Govers R, Müller-Esterl W (2006) Subcellular targeting and trafficking of nitric oxide synthases. Biochem J 396:401-409

Pacher P, Beckman JS, Liaudet L (2007) Nitric oxide and peroxynitrite in health and disease. Physiol Rev 87:315-424

Passarino G, Montesanto A, Dato S, Giordano S, Domma F, Mari V, Feraco E, De Benedictis G (2006) Sex and age specificity of susceptibility genes modulating survival at old age. Hum Hered 62:213-220

Paul V, Ekambaram P (2011) Involvement of nitric oxide in learning \& memory processes. Indian $\mathrm{J}$ Med Res $133: 471-478$

Reif A, Grünblatt E, Herterich S, Wichart I, Rainer MK, Jungwirth S, Danielczyk W, Deckert J, Tragl KH, Riederer P, 
Fischer P (2011a) Association of a functional NOS1 promoter repeat with Alzheimer's disease in the VITA cohort. J Alzheimers Dis 23:327-333

Reif A, Schecklmann M, Eirich E, Jacob CP, Jarczok TA, KittelSchneider S, Lesch KP, Fallgatter AJ, Ehlis AC (2011b) A functional promoter polymorphism of neuronal nitric oxide synthase moderates prefrontal functioning in schizophrenia. J Neuropsychopharmacol 14:887-897

Sheikh JI, Yesavage JA (1986) Geriatric Depression Scale (GDS): recent evidence and development of a shorter version. Clinical gerontology: a guide to assessment and intervention. Haworth, New York, pp 165-173

So HC, Sham PC (2011) Robust association tests under different genetic models, allowing for binary or quantitative traits and covariates. Behav Genet 41:768-775

Strosznajder JB, Jeśko H, Zambrzycka A, Eckert A, Chalimoniuk M (2004) Age-related alteration of activity and gene expression of endothelial nitric oxide synthase in different parts of the brain in rats. Neurosci Lett 370:175-179

Taddei S, Virdis A, Ghiadoni L (2001) Age-related reduction of $\mathrm{NO}$ availability and oxidative stress in humans. Hypertension 38:274-279

Toprakci M, Ozmen D, Mutaf I, Turgan N, Parildar Z, Habif S, Guner I, Bayindir O (2000) Age-associated changes in nitric oxide metabolites nitrite and nitrate. Int J Clin Lab Res 30:83-85

Torregrossa AC, Aranke M, Bryan NS (2011) Nitric oxide and geriatrics: implications in diagnostics and treatment of the elderly. J Geriatr Cardiol 8:230-242

Tsutsui M, Shimokawa H, Otsuji Y, Ueta Y, Sasaguri Y, Yanagihara N (2009) Nitric oxide synthases and cardiovascular diseases: insights from genetically modified mice. Circ J 73:986-993

van der Loo B, Labugger R, Skepper JN, Bachschmid M, Kilo J, Powell JM, Palacios-Callender M, Erusalimsky JD,
Quaschning T, Malinski T, Gygi D, Ullrich V, Lüscher TF (2000) Enhanced peroxynitrite formation is associated with vascular aging. JExp Med 192:1731-1744

Villanueva C, Giulivi C (2010) Subcellular and cellular locations of nitric oxide synthase isoforms as determinants of health and disease. Free Radic Biol Med 49:307-316

Weitzdoerfer R, Hoeger H, Engidawork E, Engelmann M, Singewald N, Lubec G, Lubec B (2004) Neuronal nitric oxide synthase knock-out mice show impaired cognitive performance. Nitric Oxide 10:130-140

Wigginton JE, Cutler DJ, Abecasis GR (2005) A note on exact tests of Hardy-Weinberg equilibrium. Am J Hum Genet 76:887-893

Wink DA, Hines HB, Cheng RY, Switzer CH, Flores-Santana W, Vitek MP, Ridnour LA, Colton CA (2011) Nitric oxide and redox mechanisms in the immune response. $\mathrm{J}$ Leukoc Biol 89:873-891

Yang B, Larson DF, Watson RR (2004) Modulation of iNOS activity in age-related cardiac dysfunction. Life Sci 75:655-667

Yoon HJ, Cho SW, Ahn BW, Yang SY (2010) Alterations in the activity and expression of endothelial NO synthase in aged human endothelial cells. Mech Ageing Dev 131:119-123

Zhou QG, Hu Y, Hua Y, Hu M, Luo CX, Han X, Zhu XJ, Wang B, Xu JS, Zhu DY (2007) Neuronal nitric oxide synthase contributes to chronic stress-induced depression by suppressing hippocampal neurogenesis. J Neurochem 103:1843-1854

Zoubovsky SP, Pogorelov VM, Taniguchi Y, Kim SH, Yoon P, Nwulia E, Sawa A, Pletnikov MV, Kamiya A (2011) Working memory deficits in neuronal nitric oxide synthase knockout mice: potential impairments in prefrontal cortex mediated cognitive function. Biochem Biophys Res Commun 408:707-712 